\title{
Artefactos culturales para el desarrollo de la literacidad académica en estudiantes universitarios indígenas
}

\section{Cultural artifacts for the development of the academic literacy of indigenous college students}

DOI: https://doi.org/10.32870/dse.v0i23.766

Juan Carlos Silas-Casillas*

Karla Susana Lombardi González**

\begin{abstract}
Resumen
El objetivo de la investigación es dar cuenta de cómo los artefactos culturales utilizados en el acompañamiento académico de un estudiante indígena de primer ingreso a licenciatura favorecen el desarrollo de la literacidad. Se muestra, a través del estudio de caso de una intervención desarrollada en una universidad privada en el Occidente de México, que buscaba desarrollar las habilidades de literacidad académica de estudiantes indígenas de nuevo ingreso a la educación superior. Con base en los conceptos de literacidad académica de Zavala $(2009,2011,2013)$, el análisis de la lengua de Van Dijk (2008) y fundamentalmente, el esquema de Salazar (2015), que enuncia las tres dimensiones de la literacidad: 1) lingüística, 2) cognitiva y 3) sociocultural; así como el concepto de artefacto cultural de Holland y Cole (1995). Se llega a la conclusión de que existen artefactos culturales físicos importantes en el desarrollo de la literacidad académica, que se ven complementados por artefactos simbólicos que permiten al estudiante indígena retratar sus experiencias de vida y sus elementos significativos en la tradición académica, y viceversa.
\end{abstract}

Palabras clave: literacidad - estudiante indígena - educación superior - artefacto cultural.

\begin{abstract}
Our research work aims to show how the cultural artifacts used in the academic accompaniment of an indigenous undergraduate student favor the development of literacy, through a case study of an intervention developed in a private university in western Mexico that sought to develop the academic literacy skills of first-year university indigenous students. It is based on concepts such as Zavala's academic literacy (2009, 2011, 2013), Van Dijk's analysis of language (2008) and especially the scheme elaborated by Salazar
\end{abstract}

* Doctorado en Educational Policy and Leadership. Maestría en Educación y Licenciatura en Psicología Educativa. SNI I. Investigador y docente en el Departamento de Psicología, Educación y Salud. Coordinador del Doctorado Interinstitucional en Educación. ITESO. Temas de investigación: balance público-privado en la educación superior, la relación entre las instituciones educativas y la comunidad y el pensamiento científico-crítico en alumnos universitarios. México.silasjc@iteso.mx

** Doctorante en Educación, Maestría en Comunicación de la Ciencia y la Cultura, especialización en Políticas Culturales y Gestión Cultural. Profesora del departamento de Lenguas, y de Psicología, Educación y Salud, ITESO. Integrante del equipo de investigación interdepartamental con el tema de literacidad académica y estudiantes universitarios indígenas. México. klombardi@iteso.mx 
(2015) that states the three dimensions of literacy: 1) linguistic, 2) cognitive and 3) sociocultural, as well as Holland and Cole's concept of cultural artifact (1995). We concluded that there are important physical cultural artifacts in the development of academic literacy, which are complemented by symbolic artifacts that allow indigenous students to portray their life experiences and significant elements in the academic tradition, and vice versa.

Keywords: literacy - indigenous student - higher education - cultural artifact.

\section{Introducción}

Desde finales del siglo pasado, pero fundamentalmente a partir del año 2000, a raíz de cambios constitucionales y el desarrollo de proyectos y programas federales, en México se inició un fuerte proceso de inclusión de estudiantes indígenas en la educación superior. Las presiones políticas y luchas reivindicatorias de distintos actores sociales tuvieron un peso importante en estas decisiones en prácticamente todo el continente americano, siendo el movimiento zapatista el más evidente en México. El Ejercito Zapatista de Liberación Nacional (EZLN), que salió a la luz el 1 de diciembre de 1994 pero llevaba bastantes años fraguando su accionar en Chiapas, hizo evidente el dramático abandono en que se encontraban -y se encuentran- las comunidades indígenas. Aunque el foco de este texto no está en la trascendencia de los movimientos sociales ni en las iniciativas nacionales para favorecer el acceso a la población indígena a mayores oportunidades educativa, sino en estrategias muy concretas de desarrollo de la literacidad de los estudiantes indígenas en educación superior, se busca no soslayar la trascendencia de estos antecedentes. Por ello es por lo que se puede señalar que a partir del año 2000 se desarrollaron distintas iniciativas, que van desde crear nuevas instituciones con un enfoque nominalmente intercultural, hasta programas para favorecer la inclusión de estudiantes indígenas en programas de licenciatura convencionales, dentro de instituciones convencionales (Olivera, Dietz, 2017). El acceso del estudiante indígena a los programas de educación superior no solo vincula las circunstancias académicas y científicas que competen a la formación universitaria, también permite traer las experiencias socioculturales situadas de cada estudiante al mundo de la academia (Herrera, 2006).

Al poner frente a frente la diversidad cultural del mundo indígena con el ambiente académico, se va construyendo una serie de procesos que implican reconocer ambos mundos en un entorno de productividad. Es justo en este entorno que la literacidad toma un papel importante, especialmente en la forma en que los estudiantes indígenas desarrollan las habilidades para producir textos disciplinarios académicos. En este sentido, "la lectura y la escritura se conciben no sólo como herramientas didácticas para el aprendizaje disciplinario sino como estructuras sociales de desarrollo" (Zavala, 2013), donde están en juego diversas situaciones socioculturales, identitarias y lingüísticas, de tensiones y conflicto en la lucha por la reconstrucción de significados que pueden dialogar con sus culturas originales. 
Los procesos institucionales de la literacidad científica académica juegan un papel importante en las nociones simbólicas de los estudiantes y en las formas de aprender la disciplina científica. Para el universitario indígena que procede de contextos culturales comunitarios, dichos proceso en los cuales interviene la lectura y la escritura disciplinar para la apropiación de los lenguajes académicos, son una de las tareas que requieren espacios de acompañamiento que propicien el uso de diversos artefactos culturales para el desarrollo de la literacidad académica.

Este texto da cuenta de una experiencia de trabajo en habilidades de literacidad académica con estudiantes indígenas en una institución de educación superior. Se trata de un estudio de caso desarrollado en una universidad particular en el Occidente de México. En las siguientes secciones se presenta el fenómeno en estudio, la perspectiva teórica, el encuadre metodológico, los resultados y una parte final que bosqueja conclusiones.

\section{Recorte del objeto}

En la última década del siglo pasado, dada la fuerte presión, por un lado, de movimientos sociales que exigían la mejora en las condiciones materiales de las poblaciones indígenas (salud, educación, justicia, etc.), así como el reconocimiento de su libre autodeterminación, y por otro lado, de las presiones políticas tanto de fracciones de partidos de izquierda como de organismos internacionales, en América Latina se vivieron trasformaciones en los marcos normativos nacionales en favor de los pueblos originarios. La modificación del artículo segundo de la Constitución en el año 2001, que reconoce el carácter multicultural de la nación, y la creación de las Universidades Interculturales con financiamiento público a partir de 2004, parecieron ser un impulso a la incorporación de los jóvenes indígenas en la educación superior. A ello se suman programas de inclusión de estudiantes indígenas en Instituciones de Educación Superior (IES) convencionales (ANUIES-Fundación Ford, 2005; ANUIES, 2006; Romo, 2005; Didou, 2006). En México, los programas para el acceso de los jóvenes indígenas a las universidades se enmarcan en una política de equidad (Navarrete, Alcántara, 2015) para facilitarles obtener espacios educativos desde sus condiciones socioculturales y económicas. Sin embargo, los resultados son marginales, especialmente en las posibilidades de permanencia y logro del estudiante indígena. Canul, Fernández, Cruz y Ucan (2008) citan a la Asociación Nacional de Universidades e Instituciones de Educación Superior (ANUIES) y su Programa de Apoyo a Estudiantes Indígenas en Instituciones de Educación Superior (PAEIIES) para ilustrar que, mientras $80 \%$ de los jóvenes mexicanos urbanos de ingreso medio podrían aspirar a la educación superior, en la población rural juvenil solo $3 \%$ puede tener acceso; como consecuencia, únicamente $1 \%$ de los muchachos indígenas ingresa a instituciones de educación superior y menos de uno de cada cinco de los que entraron terminan sus estudios y se titulan.

Estas estadísticas invitan a reflexionar sobre dos planos: primero, la efectividad de las políticas y los programas educativos de las instituciones educativas superiores que intentan adoptar 
las ideas y prácticas de la interculturalidad; y segundo, las características del proceso que vive el estudiante indígena durante su tránsito en los estudios universitarios frente al canon académico.

En el caso concreto de este estudio, con la finalidad de reservar la identidad de la institución y la persona participante, solo se dirá que se trata de una universidad privada ubicada en una urbe grande en el Occidente de México, con décadas de antigüedad y matrícula en pregrado y posgrado que rebasa los diez mil alumnos. Esta institución, en 1988 dio sus primeros pasos en la materia, otorgando becas a estudiantes que no contaban con recursos económicos suficientes para el pago de sus colegiaturas. En el año 2000 se integraron alumnos indígenas como parte de un programa de apoyo social, encargado de integrar a la institución a jóvenes de comunidades indígenas, rurales y de sectores populares. En 2002 se afinó la visión, incorporando muchachos indígenas como alumnos regulares de la universidad, entendiéndolos como "un grupo marginado que cuenta con características culturales particulares, y que se busca integrarlos a la universidad para enriquecer a su población estudiantil" (Ceja, 2013: 29).

Lo usual es que cada año aspiren ingresar a la universidad entre 30 y 40 estudiantes indígenas, sin embargo, no todos lo logran ya que no alcanzan a cumplir con los requisitos de admisión. Por otro lado, la universidad tiene un número reducido de becas asignadas a este programa y se "liberan" los lugares hasta que egresen los beneficiarios (Ceja, 2013).

Pese a contar con "asambleas" mensuales, los jóvenes no tienen un acompañamiento en el desarrollo de habilidades de lectura y escritura relativas a las disciplinas que cursan. Se enfrentan a exigencias escolares, como son la comprensión de textos disciplinales o la redacción de trabajos con normas académicas establecidas.

En octubre de 2018 se ofreció a los estudiantes indígenas que apenas iniciaban su licenciatura ese semestre un acompañamiento extracurricular para apoyarlos en sus procesos de lectura, escritura y oralidad académica de sus materias cursadas. Este acompañamiento parte del reconocimiento de la situación personal de cada muchacho, su cultura, su lengua y sus habilidades de aprendizaje. Exigía el compromiso de estudio de parte de los alumnos y participar de forma ininterrumpida en cada una de las sesiones semanales.

El trabajo con los jóvenes indígenas universitarios tuvo dos facetas; por un lado, se trató de una intervención institucional con sus estudiantes y, por el otro, como un proyecto de investigación que buscó responder la siguiente pregunta: ¿Cuáles son los artefactos culturales que median en el desarrollo de la literacidad académica de los estudiantes universitarios indígenas que asisten al acompañamiento académico? Las decisiones metodológicas para dar respuesta a la pregunta de investigación se desarrollarán con mayor amplitud en la sección correspondiente.

\section{Marco teórico}

La propuesta teórica que da soporte a este proyecto toma como eje los elementos de la lectura y escritura académica, vista desde las habilidades académicas que implican tres dimensiones: 1) 
la lingüística, 2) la cognitiva, y 3) la sociocultural. En la parte sociocultural, se revisan tres nociones clave para la concepción y problematización del término de literacidad: $a$ ) la comprensión del término de literacidad visto desde la postura sociocultural, más sociolingüística; $b$ ) la cuestión de las prácticas sociales, situadas en contextos significativos desde las distintas comunidades culturales; c) la noción que vincula las dos mencionadas, referente a la literacidad académica, ligada a la construcción social del conocimiento y desde donde se objetiva la cultura a través de las prácticas institucionalizadas de la lectura y escritura en ambientes académicos.

A continuación, se presentan las dimensiones enunciadas como constitutivas del desarrollo de la habilidad. Después, se profundiza en el concepto de literacidad desde una visión sociocultural en ambientes académicos. Desde esta perspectiva, se define lo que se entiende por prácticas y artefactos culturales en relación con estas dimensiones.

\section{Dimensiones constitutivas de la lengua}

Van Dijk (2008) propone visualizar la lengua desde tres dimensiones para su estudio: una, que parte del estudio del lenguaje; otra, que se basa en los estudios de comunicación y cognición; y la última, se basa en las situaciones de carácter social. Estas dimensiones no se identifican de manera aislada, sino que se construyen de forma en que interaccionan unas con otras. Por tanto, las habilidades académicas de la lectura y escritura se perfilan hacia el estudio de la lingüística, lo cognitivo y lo social como elementos que organizan discursos y dan sentido a lo académico.

La dimensión lingüística, compete a los fundamentos gramaticales y discursivos, que sirven para conocer el principio comunicativo del texto y cómo se organiza la información discursiva. Se caracteriza por cuatro niveles: léxico, morfológico, sintáctico y textual, que se desarrollan en los procesos académicos propios del registro de una profesión (Salazar, 2015).

La dimensión cognitiva se apoya en las teorías del desarrollo, y estudia los "procesos cognitivos que desarrolla el sujeto al momento de escribir, incluye los procesos metacognitivos de planeación, revisión y el conjunto de actividades que realiza el sujeto escritor para la detección y solución de problemas textuales en la escritura" (Salazar, 2015: 6). Lectura y escritura cobran sentido desde la perspectiva del conjunto de habilidades desarrolladas durante el proceso de elaboración de un texto.

La dimensión social, considera a la lectura y escritura "como una práctica social que se significa en el contexto social en el que interactúan tanto escritor como lector" (Salazar, 2015: 8). En esta dimensión se incluyen los nuevos estudios de literacidad, la perspectiva sociocognitiva, la sociocultural y la de alfabetización académica.

\section{Literacidad}

El término literacidad es un concepto que proviene del inglés Literacy, "surgió en el Reino Unido, como una propuesta que incluye eventos mediados por textos escritos implicados en diferen- 
tes contextos sociales (no sólo académicos)" (Moreno, 2014: 293). Inicialmente, su traducción al español refería a la "alfabetización", que separaba a sociedades letradas y no letradas, caracterizadas por sus formas de organización y, las últimas, arraigadas más en tradiciones orales que en escritas (Aimes, 2002).

Este planteamiento, que dividía a las sociedades por sus características letradas y orales, se puso a discusión a través de los trabajos de Street (1995), quien analiza que la escritura, más allá de los aspectos técnicos, está inserta en un contexto social específico. Está dentro de procesos de textualidad que trascienden el mero uso de grafías, por lo que se amplía significativamente la percepción y definición de texto. Ante esto, no se trata solamente de desarrollar los procesos cognitivos propios de las habilidades superiores implicadas en la lectura y escritura que llevaría a cabo el lector y escritor, abstraído del mundo circundante, sino de cualquier producto humano que tenga una intención comunicativa situada (Aimes, 2002).

Los estudios y prácticas de la literacidad han sido abordados desde tres perspectivas: 1) la del modelo autónomo, que explica la literacidad como una habilidad cognitiva. "Esto significa considerar a la cultura escrita como un conjunto de habilidades, técnicas y un conocimiento cognitivo universal que puede ser aprendido independientemente a los marcos culturales" (Aimes, 2002: 72); 2) la funcional, que explica la literacidad en términos de lo que las personas están habilitadas o no para hacer frente a las exigencias de la sociedad, "esto implicaba que el tipo de habilidades que se desarrollaba estaba más relacionada a los distintos usos de la escritura" (Aimes, 2002: 77); y 3) la perspectiva social, que considera sus usos en contextos particulares (Moreno, 2014), e "implica una manera de usar la lectura y la escritura en el marco de un propósito social específico" (Zavala, 2009: 23).

Desde estas perspectivas, la base conceptual de la literacidad implica que los textos consideran habilidades comunicativas para comprender distintos lenguajes que son producidos en un momento y en una cultura particular; por ello, su análisis debe considerar también el contexto situado en el que se produjeron. Particularmente, la última perspectiva de la literacidad se relaciona con los llamados Nuevos Estudios de Literacidad (NEL), que involucran trabajos de investigación desde una mirada inductiva, etnográfica, que analiza textos a la luz de las prácticas socioculturales de literacidad. En síntesis, lectura y escritura son comprendidas como actividades ligadas a prácticas sociales más amplias, inmersas en contextos dinámicos que enfatizan lo comunitario y el papel del entorno.

Las habilidades de lectura y escritura no son individuales, ni están centradas exclusivamente en contextos escolares; se entienden como prácticas sociales que cobran sentido en una comunidad específica en la media en que se nutren de los elementos de un contexto sociocultural y una cultura, donde surgen maneras vernáculas de ver el mundo, sirviendo intereses específicos (Barton y Hamilton, 2000; Street, 1995). Desde la perspectiva sociocultural, los textos también denotan relaciones de poder, ya que "en sus lenguajes están inmersas relaciones 
de dominación-subordinación, que dan pertenencia a unos pocos y marginalidad al resto. Así, los textos son un poderoso factor para construir identidades y configurar formas de conocer y actuar" (Gayol, 2014, s/p). En este orden de ideas, existen estudios que explican las prácticas de literacidad académica desde esta perspectiva de poder, que configuran las identidades disciplinares de los estudiantes en contextos lingüísticos y culturales determinados (Lea, Stierer, 2000; Hernández, 2016; Zavala, 2009; Moreno, 2014).

Las prácticas que conforman la literacidad involucran "valores, actitudes, sentimientos y relaciones sociales que son procesos internos del individuo y que no son siempre observables. Se trata de maneras de leer y escribir que articulan construcciones particulares de la realidad y que sólo tienen sentido en el marco de éstas" (Zavala, en Cassany, 2009: 25).

Barton y Hamilton (en Zavala, Niño-Murcia, Aimes, 2004: 113) han definido seis principios para explicar el uso social de la escritura:

1. Se entiende como un conjunto de prácticas sociales, que se pueden inferir a partir de los hechos de escritura, que a su vez están mediados por textos escritos.

2. Las formas de literacidad están asociadas a diferentes ámbitos de la vida.

3. Las prácticas de literacidad están organizadas por instituciones sociales y relaciones de poder, de manera que algunas son más dominantes, visibles e influyentes que otras.

4. Las prácticas de literacidad cumplen propósitos específicos y forman parte de objetivos sociales y prácticas culturales más amplias.

5. La literacidad está situada históricamente.

6. Las prácticas de literacidad cambian debido a distintos procesos culturales, y las nuevas formas se adquieren a partir de procesos de aprendizaje informal y de atribución de significados.

El papel de la cultura cobra un sentido particular en la práctica social de la lectura y la escritura ya que está ligada al uso de textos en contextos específicos, situados sociohistóricamente e institucionalizados de forma más o menos clara, donde se ponen en juego relaciones de poder a través del uso del conocimiento y de la lengua. Sin embargo, pese a que la cultura marca posibilidades para que los individuos desarrollen distintas maneras de conocer y de percibir una realidad, también "se trata de procesos subjetivos en permanente negociación que construimos discursivamente y que están afectados por estructuras de poder (Zavala, 2011:2).

\section{Literacidad académica}

Las prácticas sociales de la literacidad están ligadas a la construcción social del conocimiento. Desde esta perspectiva, los Nuevos Estudios de literacidad (NEL) cuentan con una línea de investigación en la que, en diferentes momentos, autores como Clark e Ivanic (1997), Hirst (2004), 
Haggis (2003), Lillis (1997, 2001, 2003) o Lynn (2000), han contribuido al desarrollo del concepto de literacidad académica, que se desarrolla en los espacios de educación superior.

Para Zavala (2011), la literacidad académica es una manera particular de usar el lenguaje, desarrollado a partir de la tradición intelectual de Occidente, y que por sus características de trasmisión, -neutral-, según Turner (2003), se oculta en un "discurso de transparencia" asumiéndose como la manera óptima que garantiza la formulación clara y la comprensión de contenidos académicos dentro de comunidades científicas. El discurso científico que subyace "objetivamente" en la literacidad académica, no es más que una manera validada de construir conocimiento de acuerdo con las convenciones establecidas desde la tradición intelectual dominante (Zavala, 2011). Desde esta mirada, los estudios de la literacidad académica discuten las posturas ideológicas, el contenido informativo que se refleja en los procesos de lectura y escritura académica, las cuales se estructuran como prácticas letradas dominantes (Vargas, 2013).

El estudio de la literacidad académica ha permitido poner en la discusión de expertos e interesados algunos aspectos que no se habían percibido inicialmente. Uno de ellos es el referente a la postura del estudiante sobre la escritura, muchas veces invisibilizada frente a las prácticas de elaboración de textos que siguen los esquemas validados por la academia. En este sentido, las perspectivas de análisis de textos y sus fuentes, incluyen distintas dimensiones tales como:

el impacto de las relaciones de poder en la escritura del estudiante, el papel central que tiene su identidad en la escritura académica, la concepción de la escritura como construcción de conocimiento inscrita ideológicamente, así como la disciplinariedad específica de las prácticas de escritura (Zavala, 2011: 55).

La literacidad académica adopta una postura crítica y busca dilucidar las asimetrías de poder y de "legitimidad escolástica". Desde esta perspectiva, la postura crítica que se construye en el comparativo entre ambas nociones (alfabetización académica y literacidad académicas) busca, a través de la noción de "las prácticas institucionales del misterio" de Lillis (1997) (se refiere a formas específicas de usar el lenguaje que se convierten en un misterio porque su significado está velado para aquellos que conviven inicialmente en un contexto específico), dar cuenta de dimensiones invisibilizadas que perjudican a aquellos culturalmente distantes a los contextos de la universidad, pues sus modos de hacer y decir en cada contexto tienen sus convenciones.

Para Canagarajah (2003), la escritura académica se asocia con identidades raciales y el estudiante, al enfrentarse con ellas, muestra acomodación y resistencia a la apropiación de los cánones de esa escritura. Zavala (2011), sin embargo, matiza las ideas y menciona que no es suficiente analizar y cuestionar la literacidad como un discurso con relaciones de poder creado por la historia, sino que es preciso entenderla como práctica social. Es en esta donde son evidentes "maneras habituales (vinculadas a tiempos y lugares particulares) en las que la gente aplica recursos (materiales y simbólicos) para actuar juntos en el mundo" (Chouliaraki, Fairclough, 1999: 21). 


\section{Artefactos culturales y mediaciones}

Según los Nuevos Estudios de Literacidad, una forma de entender las prácticas de lectura y escritura es a través de los artefactos culturales; cuya etimología se conforma de ars o arte y facto, es decir, lo que es hecho con arte. Se define propiamente "a partir de las competencias que podían ser útiles para el manejo de los soportes de lectura convencionales -básicamente el libro o material escriturario en todas sus variantes, desde un cuaderno a una enciclopedia, plumas y otros accesorios" (Martos, Martos, 2014: 132).

Holland y Cole (1995) definen teóricamente al artefacto cultural como "piezas básicas del engranaje del ser humano con el mundo físico y de las personas entre sí". Los artefactos tienen dos características: 1) son físicos o materiales (conceptuales), por ejemplo, un lápiz que tiene la funcionalidad para escribir, y 2) son los ideales (simbólicos), es decir, que ese objeto posee un significado sociocultural que revela una significación que se le otorga culturalmente a un objeto.

Para Holland y Cole (1995), el artefacto está vinculado estrechamente con la cultura, de forma que la idea simbólica de estos se construye a partir del pensamiento y de los contextos culturales en los que se les atribuye un sentido, particularmente influenciados por la tradición. En este sentido, difícilmente se puede desvincular un concepto del otro; están intrínsecamente vinculados, interpenetrados y se proyectan en los imaginarios sociales, en la memoria colectiva, en las cosmovisiones entre el objeto y las creencias (Castoriadis, 1999).

El estudio de los artefactos culturales invita a entrar en el mundo pluridimensional para identificar distintas esferas que se interrelacionan: 1 ) la de la cultura material, referida al objeto físico; 2) la del emprendimiento personal o individualización, que es el uso y apropiación que se le da al objeto ya sea personal o de forma colectiva; 3 ) la de la memoria o del patrimonio, la conservación del objeto en relación con los valores que forman parte de la herencia cultural o la memoria colectiva; y 4) la de la instrucción o la socialización, son enseñanzas comunitarias que se asumen o se reconocen por parte de la comunidad (Martos, Martos, 2014).

Una de las características intrínsecas de los artefactos culturales es que por la misma propiedad del objeto representativo deviene una mediación con el pasado y el signo material, aquí se asienta la noción de artefactos en lo que Vigotsky (1994) entiende como sistema mediador entre el ser humano y su entorno, capaz de posibilitar recuerdos como material de reconstrucción. Es decir, las personas están ligadas a los objetos, entre los cuales existen vínculos afectivos que están inscritos en los actos sociales, en contextos, relaciones que despliegan actitudes, aunque las cosas no estén presentes, sino en el pensamiento o en la experiencia (Mendoza, 2014: 104).

Por tanto, los artefactos culturales son parte fundamental de una cultura (académica, comunitaria, etc.) y que promueven distintas formas de ser representados y simbolizados, y pro- 
pone conectar los objetos, la oralidad, la escritura con la vida del individuo que evoquen narrativas sociales significativas para el desarrollo de la literacidad académica.

En suma, la perspectiva de la literacidad que se aborda como fundamento en este trabajo parte del posicionamiento sociocultural que sustenta a los Nuevos Estudios de la Literacidad (NEL). Corriente que señala nuevos caminos para estudiarla como una práctica social donde intervienen relaciones subjetivas que están estructuradas histórica, contextual y culturalmente en los discursos comunicativos de los textos y en relación con los mismos estudiantes.

El estudio de la literacidad académica no solo se centra en el examen minucioso de las relaciones de poder que tienen los usos de la lectura y escritura científica en los ámbitos académicos, sino también en cómo el estudiante con condiciones culturales específicas actúa frente al mundo, dialoga con los conocimientos y desarrolla acciones en el marco de los efectos de las estructuras académicas. En este sentido, se enfatiza la frase de Canagarajah (2003, en Zavala 2011: 56) cuando dice que "La nueva noción de escritura no implica un objeto, sino una actividad. Escribir ya no es sólo un producto (lingüístico) o un proceso (cognitivo), sino una práctica situada, social, material, ideológica e histórica".

En la siguiente sección se describe la manera en que se desarrollaron tanto la intervención institucional con el acompañamiento tutorial a los estudiantes indígenas como la forma en que se sistematiza y analiza la información con base en las ideas de Salazar (2015).

\section{Decisiones metodológicas}

Dado que este proyecto busca explicar cómo los artefactos culturales utilizados en el acompañamiento académico a estudiantes indígenas de primer ingreso de licenciatura favorecen el desarrollo de la literacidad, las decisiones se orientan hacia dar cuenta del proceso de cambio a partir de las características que competen al estudiante indígena como universitario.

Con la finalidad de mostrar los procesos y vivencias, el enfoque cualitativo es el más conducente para aprehender los significados que tiene para los participantes estar en la universidad, y al mismo tiempo favorece la posibilidad de dar cuenta de procesos de interacción humana. El interés de la investigación cualitativa es entender una situación social particular, un evento, rol, grupo o interacción (Locke, Spirduso, Silverman, 1987). Es un proceso de investigación amplio en el que se va logrando la comprensión del sentido de un fenómeno social por contraste, comparación, replicación, catalogación y clasificación del objeto de estudio (Miles, Huberman, 1984). Este proceso implica la inmersión en la vida cotidiana del entorno elegido para el estudio, donde el investigador ingresa en el mundo de los informantes y, a través de la interacción en curso, ve las perspectivas y sentidos de los informantes (Marshall, Rossman, 1989). Por tanto, la investigación cualitativa pretende acercarse al mundo de "ahí fuera" para describir y algunas veces explicar fenómenos sociales "desde el interior" (Flick, 2004). 
Al tratarse del análisis minucioso del trabajo de promoción de literacidad académica con un alumno, se asume este como un estudio de caso, mismo que se entiende como el estudio en profundidad de una sola unidad de análisis (un fenómeno relativamente determinado) donde el académico intenta contribuir a esclarecer las características de un grupo más grande o un fenómeno similar (Gerring, 2004: 341).

Para este estudio se entiende, junto con Yin (2003), que se trata de la estrategia idónea para dar respuesta a preguntas relativas a ¿cómo? o ¿por qué?, cuando el investigador tiene poco control sobre los eventos y cuando el foco está en un evento actual (contemporáneo) en un contexto real. Para Ragin y Becker (1992), la parte importante es delimitar o construir el caso, él lo llama Casing, en inglés, y se trata en sí mismo de una operación en el proceso de investigación que involucra relacionar conceptos y evidencia empírica. Por ello se asume que este es un estudio de caso cuyo recorte de fenómeno es construido para dar cuenta desde las tres dimensiones del modelo de Salazar (2015): lingüística, cognitiva y sociocultural.

Las siguientes páginas muestran de forma muy esquemática estas dimensiones. Es importante señalar que el esquema macro es el de Salazar (2015), sin embargo, se complementa y fortalece con algunos elementos aportados por otros teóricos de la literacidad. Se hace referencia al autor complementario cuando es necesario. 


\section{Tabla 1. Dimensiones de la literacidad académica}

\begin{tabular}{|c|c|}
\hline $\begin{array}{l}\text { ILLL: Elenenlus } \\
\text { orhambativos del taxto }\end{array}$ & 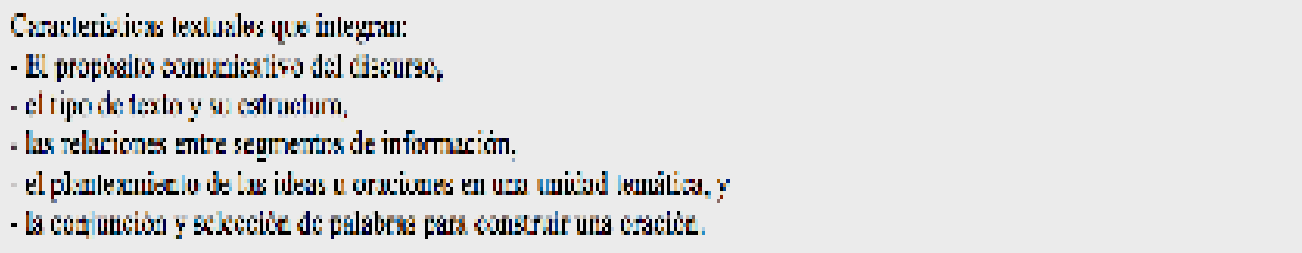 \\
\hline 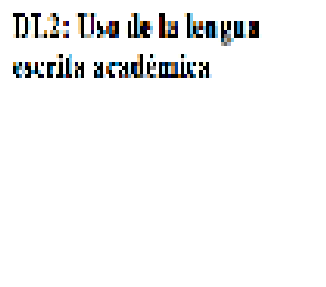 & 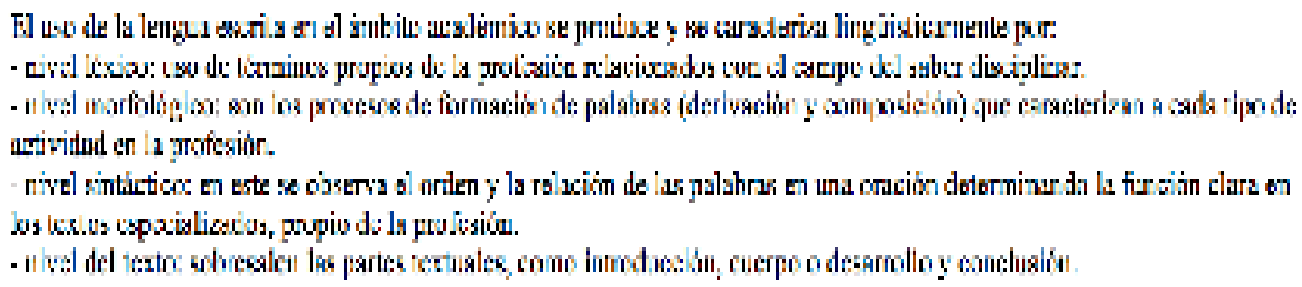 \\
\hline $\begin{array}{l}\text { IJL.5: Goherlán y } \\
\text { enterenciu textual }\end{array}$ & 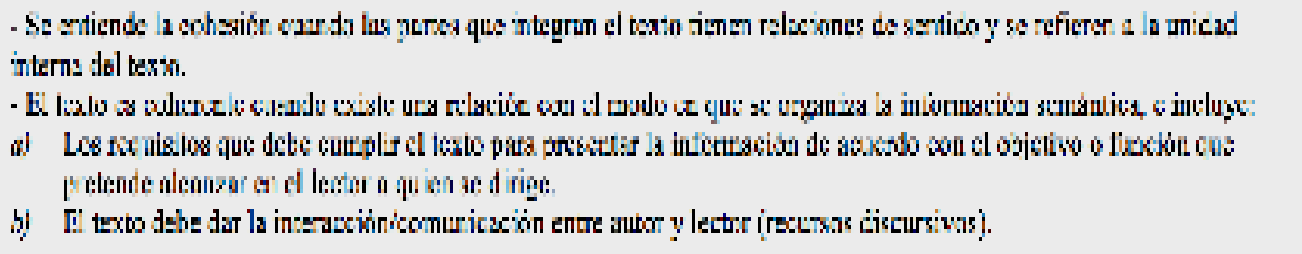 \\
\hline 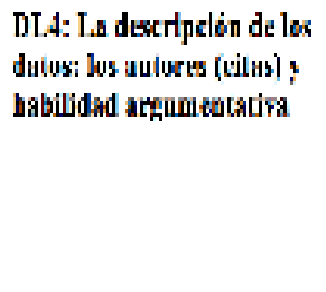 & 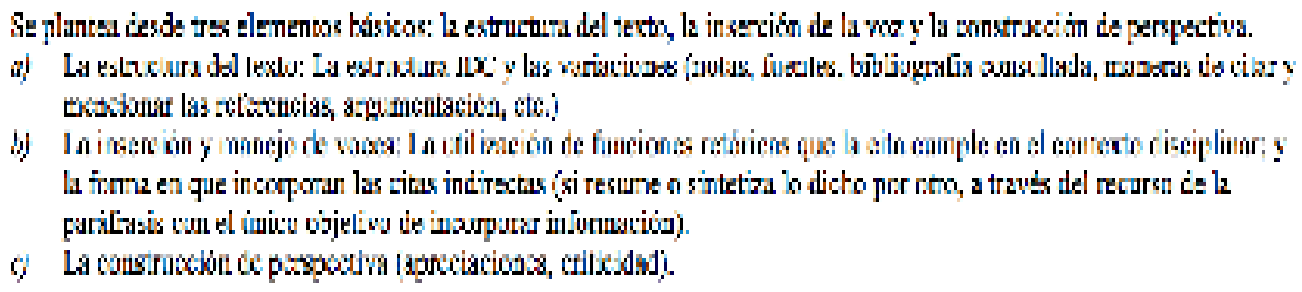 \\
\hline
\end{tabular}

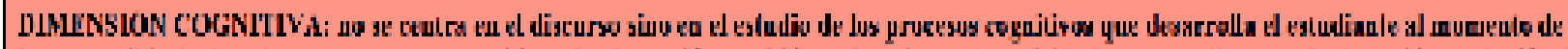

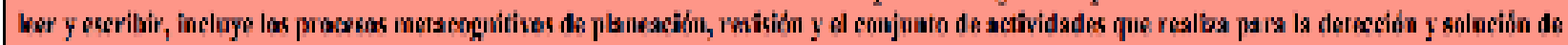

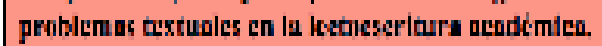

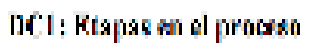
du lu lowiu $\mathrm{ra}$

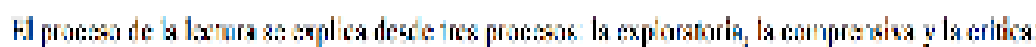

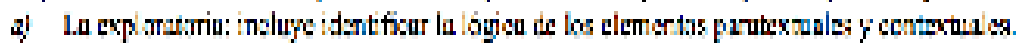

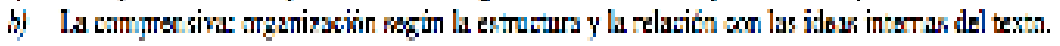

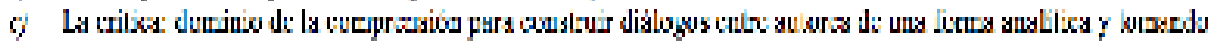
jothing 


\begin{tabular}{|c|c|}
\hline $\begin{array}{l}\text { DC2: Etapas del proceso } \\
\text { de la escritura }\end{array}$ & $\begin{array}{l}\text { El proceso de escritura se explica a partir de tres procesos: la planeación, la escritura y la } \\
\text { revisión. } \\
\text { a) La planeación incluye: plantear tema y objetivo, acopio y generación de ideas, organización } \\
\text { y jerarquización. } \\
\text { b) La escritura en función del lenguaje correspondiente, de acuerdo con la información. } \\
\text { c) La revisión textual de acuerdo con ciertos parámetros textuales. }\end{array}$ \\
\hline $\begin{array}{l}\text { DC3: Proceso de } \\
\text { Aprendizaje }\end{array}$ & $\begin{array}{l}\text { En el proceso de aprendizaje incluye: } \\
\text { a) Entender el proceso de lectoescritura, flexible y no estática, referente a que pueden variar las } \\
\text { estructuras y jugar con los componentes. } \\
\text { b) Conoce y es consciente de los componentes de los textos y las etapas de la lectoescritura. } \\
\text { c) Persona metacognitiva: consciente de sus procesos cognoscitivos y con capacidad de regular } \\
\text { sus operaciones mentales cuando escribe. } \\
\text { d) La ejercitación de la lectura y escritura como un proceso natural mientras se va ejercitando. }\end{array}$ \\
\hline \multicolumn{2}{|c|}{$\begin{array}{l}\text { DIMENSION SOCIOCLLTURAL: parte de la idea de considerar la lectura y eseritura como una práetica sacial que se } \\
\text { significa en el contexto social en el que interactúan tanto escritor como lector. }\end{array}$} \\
\hline $\begin{array}{l}\text { DS1: EI contexto social y } \\
\text { ambiental }\end{array}$ & $\begin{array}{l}\text { Aspectos sociales y culturales que inciden en la composición escrita (identidad, trayectorias, } \\
\text { procedencia). Aspectos espaciales-ambientales: la influencia del espacio de interaceión. }\end{array}$ \\
\hline DS2: La regulación & $\begin{array}{l}\text { La regulación de la escritura "enfatiza la importancia de varios factores cognitivos, conductuales, } \\
\text { afectivos-motivacionales y ambientales que intervienen en toda actividad de cseritura y que deben } \\
\text { ser regulados a fin de lograr unos determinados objetivos" (Castelló, 2010: 1265). }\end{array}$ \\
\hline $\begin{array}{l}\text { DS3: Vinculos entre el } \\
\text { texto, sujeto y contexto }\end{array}$ & $\begin{array}{l}\text { Fi significado del texto no está en el texto ni en el sujeto lector sino en el contexto social en el } \\
\text { que interactían tanto escritor como lector, en la comunidad cultural a la que pertenecen, y en el } \\
\text { conocimiento sociocultural del grupo social humano al que se refiere el texto. }\end{array}$ \\
\hline $\begin{array}{l}\text { DS4: Alfahetización } \\
\text { Académica }\end{array}$ & $\begin{array}{l}\text { "El proceso de enseñanza que puede (o no) ponerse en marcha para favorecer el acesso de los } \\
\text { estudiantes a las diferentes culturas escritas de las disciplinas" (Carlino, 2013, p. 370). }\end{array}$ \\
\hline
\end{tabular}

Como técnicas para la obtención de la información se utilizaron las usuales para este tipo de estudios: entrevista semiestructurada, observación y análisis de los trabajos elaborados para las asignaturas de otros profesores que se revisaban en las sesiones. El acompañamiento se llevó a cabo durante los dos primeros semestres del ciclo escolar 2018-2019, en sesiones individuales y en ocasiones grupales, una vez por semana en un espacio (un salón de clase) especialmente reservado para ello. La persona facilitadora, miembro del personal académico de la universidad, realizó un diagnóstico en las sesiones iniciales. Con base en ello y en las necesidades expresadas por el alumno, fue planteando intervenciones específicas durante el proceso del desarrollo de habilidades que iba adquiriendo el estudiante.

Cada sesión tuvo insumos y productos específicos, muchos de ellos enfocados en los trabajos que solicitaban los profesores de las materias que cursaba el estudiante. Las sesiones de acompañamiento se registraron en bitácoras que daban cuenta de las intenciones, procesos y productos de cada sesión, como los intercambios vivenciales reportados por los alumnos. Las sesiones se audiograbaron con la anuencia expresa de los alumnos, se tomaron fotografías del pizarrón y los cuadernos empleados en las sesiones. 
El desarrollo de la literacidad académica se observa a partir de las tres dimensiones de la lectura y escritura académica: 1) la dimensión lingüística, 2) la cognitiva y 3) la sociocultural. Cada una integra distintos elementos y procesos según su objetivo. Se diseñó un esquema de análisis inductivo-deductivo (de ida y vuelta) que permite generar conocimiento desde la evidencia empírica, sin soslayar las aportaciones teóricas previas. En este caso se retoma el esquema de Salazar (2015) y se pone en diálogo con los trabajos inductivos, mismo que permitió una sistematización y análisis eficiente de la información recopilada en las sesiones. En el siguiente apartado se presentan los resultados.

\section{Resultados}

Siguiendo las premisas del enfoque sociocultural de la literacidad, este trabajo asume que el desarrollo de estas habilidades está social y culturalmente influido. Por ello es importante ofrecer información contextual del estudiante participante. Se trata de un varón de 26 años, originario de Palenque, Chiapas, perteneciente a la etnia maya, lengua ch'ol, y es estudiante del primer semestre de la licenciatura en Gestión Política Global. Tiene la intención de estudiar para apoyar a su comunidad. Se interesa en asuntos de migración, la cultura de la legalidad y entender a profundidad cómo funciona la sociedad, la democracia y la política. En la mayoría de las sesiones habla sobre las problemáticas de su comunidad en Palenque y de su participación como apoyo en un albergue para migrantes en su localidad. Menciona que no quiso estudiar la carrera en Chiapas -aunque sus papás le insistieron- ya que el sistema educativo tiene un nivel académico bajo.

En el semestre de otoño 2018, el estudiante cursó dos materias, una propia del currículum básico: Comunicación Oral y Escrita (COE); y otra relacionada a los saberes profesionales: Cultura de la Legalidad. Las sesiones de acompañamiento en el semestre de inicio comenzaron casi a mediados del ciclo, por tanto, en este primer periodo se acompañó al alumno en seis sesiones documentadas.

Al ser hablante nativo de ch'ol, conoció el español cursando la preparatoria. Tras terminar su bachillerato permaneció un tiempo sin estudiar, trabajando en su comunidad como chofer transportista de carga. A partir de esta experiencia laboral, conoce dos situaciones que recurrentemente relatará durante las sesiones de acompañamiento: las condiciones de los migrantes en Chiapas, mismas que conoció trabajando en un albergue como colaborador de apoyo; y las situaciones de carencia que viven en su comunidad.

El encuentro con el estudiante indígena fue a partir del ofrecimiento de un acompañamiento académico en literacidad académica. Él y otros compañeros accedieron, sin embargo, su caso es notable dadas sus condiciones lingüísticas, su edad -un poco por arriba del promedio universitario- y la distancia geográfica con su comunidad. Es importante mencionar que en uno de los diagnósticos realizados por la universidad indicaban que no era apto para continuar sus 
estudios, dadas sus carencias lingüísticas, cognitivas y de aprendizaje. Sin embargo, a pesar de los resultados decidió continuar.

En los próximos párrafos se resaltan tres momentos en el acompañamiento centrado en el desarrollo de las habilidades de lectura, escritura y oralidad en sus materias disciplinares.

En un primer momento, se decidió no recurrir a algún instrumento o prueba académica para identificar el nivel de aprendizaje o de las habilidades de lectoescritura del estudiante, sino que se partió de la charla informal y la narración de anécdotas de su lugar de procedencia. En esa misma sesión, mencionó tener carencias del dominio lingüístico del español y expresó su temor a enfrentarse con textos que no pudiera comprender. El diálogo abierto en el inicio del proceso permitió identificar el sentir del estudiante en relación con sus temores y motivaciones frente a la experiencia "nueva" de lo que es la vida académica, además de que favoreció que reconociera por sí mismo sus debilidades lingüísticas y cognitivas para enfrentarse a la demanda de trabajos que competen a su carrera universitaria.

En un segundo momento, durante las actividades de las sesiones, en muchas ocasiones el mismo alumno identificó que tenía problemas recurrentes en la escritura de trabajos y la comprensión lectora, específicamente, la dificultad se encontraba en la distinción de tipos de ideas y argumentos en la organización del texto académico. En las sesiones de acompañamiento, a partir de los textos de mayor dificultad, la facilitadora provocaba el diálogo de temáticas referentes a situaciones de su comunidad o de su contexto de procedencia; este hecho cobró sentido en el alumno para comprender los discursos académicos y cómo estos se organizan frente a sus formas de pensar.

En el segundo semestre, el estudiante inscribió cinco materias, la mayoría centradas en la lectura de textos literarios y académicos. Uno de sus profesores les dejaba recurrentemente analizar escritos que contenían un lenguaje poco familiar para el estudiante. Durante las sesiones de acompañamiento, el alumno mencionaba las tareas que el profesor les dejaba, que consistían en la elaboración de glosarios, reportes de lectura, comentarios, exposiciones y mapas de organización de la información. En un inicio, el alumno mencionó no tener aprecio por la lectura, sin embargo, las dinámicas que se trabajaban en las sesiones de acompañamiento fueron espacios de catarsis y de descubrimientos para expresar la dificultad de comprensión por no dominar el idioma español y sus tecnicismos; también, para que él mismo reflexionara sobre su propia lengua y descubriera formas distintas en las que se pueden nombrar y comprender las cosas desde otro sistema lingüístico.

En un tercer momento, ya avanzado el segundo semestre, el estudiante mostró mayor habilidad en la elaboración del texto académico que se le solicitaba; asimismo, en la habilidad lectora, frecuentemente vinculaba los términos y conceptos con algún evento de su contexto familiar, su memoria, su experiencia vivida, ya sea para argumentar o contraponer. Por iniciativa propia se involucró en un concurso de proyectos universitarios de impacto social, implicó para 
él distintos retos en la planeación y ejecución de la redacción y exposición de sus ideas frente a grupos de expertos del tema, su motivación principal radicaba en la obtención de un beneficio económico para gestionar su proyecto cultural relacionado con su comunidad.

En la tabla 2 se muestra de forma operativa cómo se pueden percibir los cambios en las habilidades de lectura y escritura en el alumno. Para identificarlos se tomaron en cuenta las tareas de comprensión lectora, escritas y orales, y los diálogos temáticos dentro de las sesiones de acompañamiento. Cabe mencionar que estos cambios se encuentran en una etapa básica, esto es, que aún no se apropia completamente de la estrategia o del dominio pleno de la competencia, sino que son las primeras aproximaciones para detonar cambios definitivos en las sesiones subsecuentes del siguiente periodo escolar.

Los cambios que dan cuenta del desarrollo de la literacidad académica se integran analíticamente en las tres dimensiones del modelo de Salazar (2015), que caracteriza la escritura académica:

a) Dimensión lingüística: se identifican dos cambios: el primero, se da cuenta que el texto escrito tiene una estructura; y el segundo, descubre la función y uso de algunas categorías lingüísticas.

b) Dimensión cognitiva: se identifican dos cambios en el proceso: el primero, relacionado con el descubrimiento de la construcción básica de la planeación escrita; y el segundo, al identificar la organización de ideas en la planeación escrita.

c) Dimensión sociocultural: se identifican reguladores que motivan al aprendizaje, entre ellos se encuentran los relatos recurrentes y narraciones que daban sentido a situar la práctica de la lectura y la escritura académica desde su propia historia y su contexto de interacción cotidiana.

En la tabla 2 se da cuenta de los visos de cambio observados y se agrupan de acuerdo con las tres dimensiones de Salazar (2015). Por ejemplo, cuando el estudiante reconoció y señaló la estructura que debe tener un ensayo académico, tipo de texto solicitado frecuentemente en sus clases, se entiende que está descubriendo los elementos estructurales de este tipo de textos (sub-dimensión 1.1) dentro de la dimensión lingüística. 
Tabla 2. Cambios identificados en el desarrollo de la literacidad académica

\begin{tabular}{|l|l|l|l|l|}
\hline \multicolumn{2}{|c|}{ I. DIMENSION LINGÜISTICA } & \multicolumn{2}{c|}{ 2. DIMENSION COGNITIVA } & \multicolumn{1}{c|}{$\begin{array}{c}\text { 3. DIMENSION } \\
\text { SOCIOCULTCRAL }\end{array}$} \\
\hline $\begin{array}{c}\text { Descubrimiento } \\
\text { de estructura } \\
\text { textual escrita }\end{array}$ & $\begin{array}{c}\text { 1.2 Descubrimiento } \\
\text { de categorías } \\
\text { lingüísticas }\end{array}$ & $\begin{array}{c}\text { 2.1 Descubrimiento } \\
\text { de la construcción } \\
\text { básica de la } \\
\text { planeación escrita } \\
\text { en la planeación escrita }\end{array}$ & $\begin{array}{c}\text { 2.2 Descubrimiento de } \\
\text { organización de ideas }\end{array}$ & $\begin{array}{c}\text { 3.1 Identificar } \\
\text { reguladores de } \\
\text { motivación de su } \\
\text { contexto } \\
\text { sociocultural }\end{array}$ \\
\hline $\begin{array}{l}\text { Estructura del } \\
\text { ensayo } \\
\text { académico }\end{array}$ & $\begin{array}{l}\text { Identificar las } \\
\text { sintaxis de las } \\
\text { enunciaciones }\end{array}$ & $\begin{array}{l}\text { Identificar tema y } \\
\text { título }\end{array}$ & Identificar conceptos & $\begin{array}{l}\text { El sentido de } \\
\text { pertenencia a la } \\
\text { comunidad }\end{array}$ \\
\hline $\begin{array}{l}\text { Identilicar } \\
\text { categorias }\end{array}$ & $\begin{array}{l}\text { Identilicación de } \\
\text { elementos que } \\
\text { organizan el texto }\end{array}$ & $\begin{array}{l}\text { Identilicar } \\
\text { caracteristicas del } \\
\text { propósito }\end{array}$ & $\begin{array}{l}\text { Identificar las ideas } \\
\text { principales dentro de un } \\
\text { texto }\end{array}$ & $\begin{array}{l}\text { Experiencia personal } \\
\text { distintos contextos) }\end{array}$ \\
\hline $\begin{array}{l}\text { Identilicar } \\
\text { argumentos }\end{array}$ & $\begin{array}{l}\text { Identilicar y } \\
\text { distinguir el sujeto } \\
\text { en el párrafo }\end{array}$ & $\begin{array}{l}\text { Reconoce qué le } \\
\text { hace fäla aprender y } \\
\text { qué no }\end{array}$ & Organizar las ideas & Memoria cultural \\
\hline
\end{tabular}

En las siguientes tablas (de la 3 a la 6) se desglosan los cambios (o logros) que tuvo el estudiante en las dimensiones lingüística y cognitiva, en la explicación de estas tablas se menciona como eje fundamental de su interpretación la dimensión sociocultural. También se registran cuáles fueron los artefactos, mediaciones y significaciones que intervinieron para favorecer el desarrollo de la lectura y escritura académica en el estudiante indígena universitario.

Primeramente, en las tablas 3 y 4, se muestra el análisis de la dimensión lingüística; la primera da cuenta de seis habilidades en relación con las estructuras académicas textuales; la segunda muestra tres habilidades referentes a la detección de categorías lingüísticas. 
Tabla 3. Cambios, artefactos, mediaciones y significados derivados de la Dimensión Lingüística sobre el descubrimiento de estructuras académicas textuales

\begin{tabular}{|c|c|c|c|}
\hline \multirow[b]{2}{*}{$\begin{array}{l}\text { CAMBIO: } \\
\text { bescuhrimiento de } \\
\text { estructurax } \\
\text { uendemuicas fexiuales }\end{array}$} & \multicolumn{3}{|c|}{ 1.1 DLHENSION UNGCISTICA: CALBROS ESTRC'TCRALES DEL TEXTO } \\
\hline & $\begin{array}{l}\text { Qné bizo para mêjorar } \\
\text { (Artefoctos) }\end{array}$ & $\begin{array}{l}\text { Quken se lo cuearge } \\
\text { (Hicditeinars) }\end{array}$ & $\begin{array}{l}\text { Qué le sigaificol manociodes } \\
\text { [higuifiendos] }\end{array}$ \\
\hline 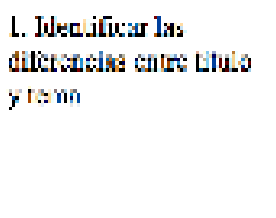 & 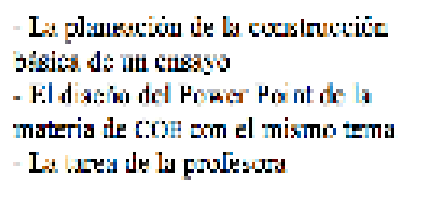 & 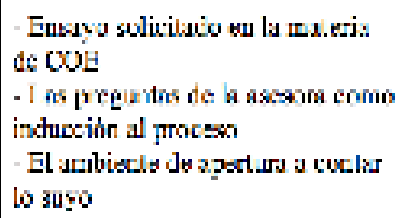 & 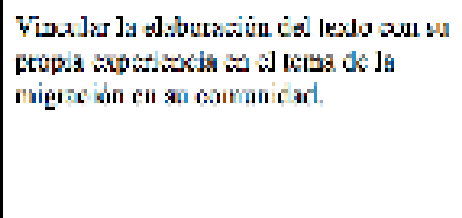 \\
\hline 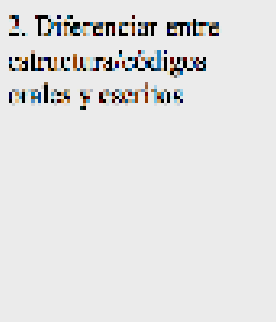 & 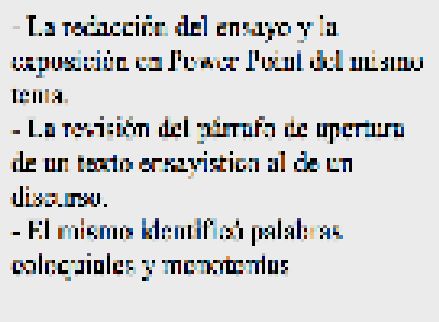 & 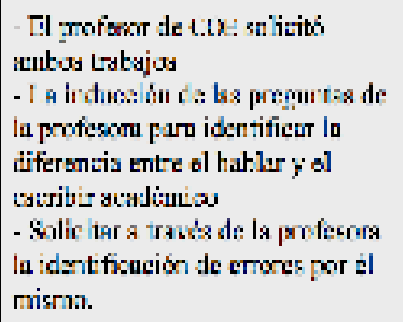 & 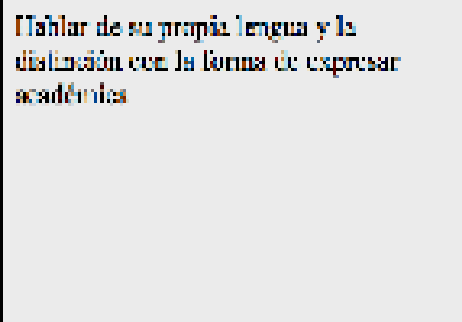 \\
\hline $\begin{array}{l}\text { 3. Ell pómafo y st } \\
\text { extructora }\end{array}$ & 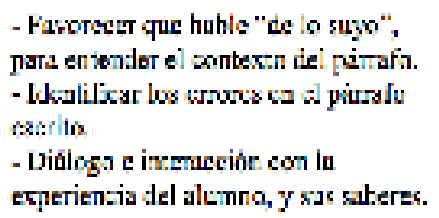 & 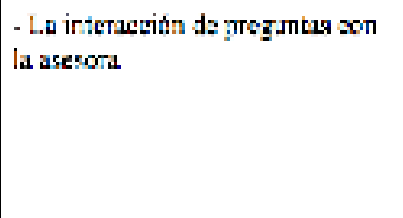 & 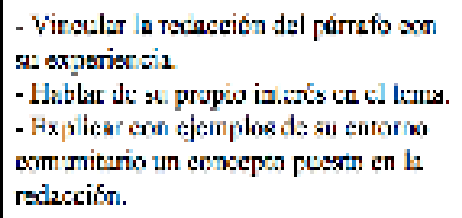 \\
\hline $\begin{array}{l}\text { 4. Arguncuad de u } \\
\text { easnyo }\end{array}$ & 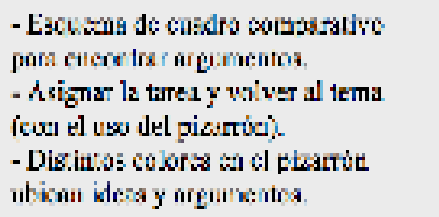 & 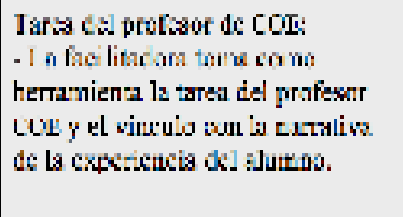 & 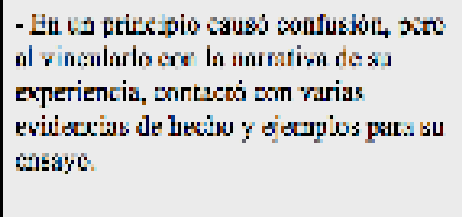 \\
\hline $\begin{array}{l}\text { 5. Mudeles de ucuen \& } \\
\text { cl censaro }\end{array}$ & 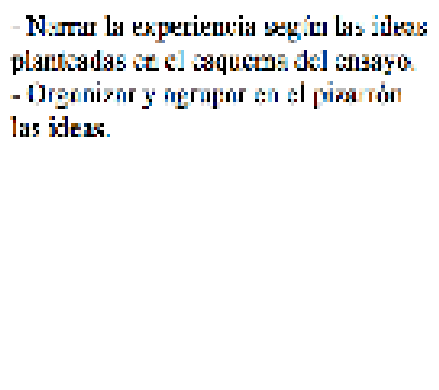 & 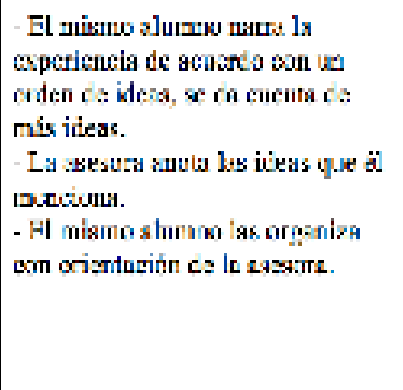 & 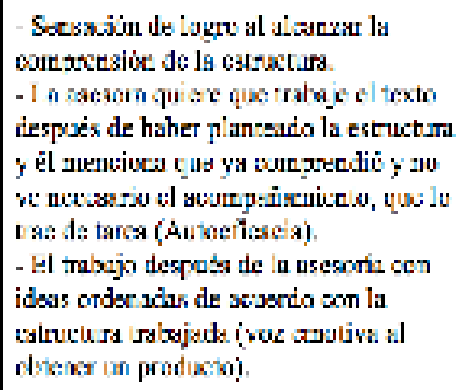 \\
\hline $\begin{array}{l}\text { f. Tdentificst } \\
\text { atgumusevs }\end{array}$ & 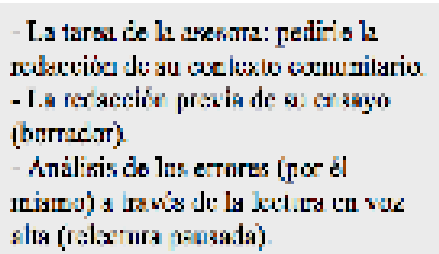 & 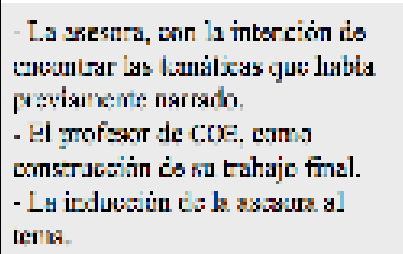 & $\begin{array}{l}\text {-.s vir zulscioin do ku experiencia cnn la } \\
\text { rabuxiós. }\end{array}$ \\
\hline
\end{tabular}


En la tabla 4, se mencionan como característica de cambio en el estudiante indígena el descubrimiento de categorías lingüísticas en un texto: se refiere a identificar la sintaxis y distinguir el sujeto en la oración y el párrafo, encontrar la concordancia entre singular y plural, y poder identificar los elementos organizadores de un texto. Se menciona a continuación cuáles artefactos se usaron, los elementos mediadores y significativos que propiciaron estos cambios.

Tabla 4: Cambios, artefactos, mediaciones y significados derivados de la Dimensión Lingüística sobre el descubrimiento de categorías lingüísticas

\begin{tabular}{|c|c|c|c|}
\hline \multicolumn{4}{|c|}{ 1.2 DIMENSION LINGUISTICA: CATEGORIAS LINGUISTICAS } \\
\hline $\begin{array}{l}\text { CAMBIO: } \\
\text { Descubrimiento de } \\
\text { categorias lingüisticas }\end{array}$ & $\begin{array}{l}\text { Qué hizo para mejorar } \\
\text { (Artefactos) }\end{array}$ & $\begin{array}{l}\text { Quién se lo encargó } \\
\text { (Mediaciones) }\end{array}$ & $\begin{array}{l}\text { Qué le significó/ emociones } \\
\text { (Signuificados) }\end{array}$ \\
\hline $\begin{array}{l}\text { 1. Identificar sintaxis y } \\
\text { distinguir el sujeto en la } \\
\text { oración y el párrafo }\end{array}$ & $\begin{array}{l}\text { - El uso de la computadora para la } \\
\text { redacción del páfrafo. } \\
\text { - Uso del pizarrón y subrayado. } \\
\text { - Asesora utilizó la narrativa } \\
\text { (experiencia) del estudiante. }\end{array}$ & $\begin{array}{l}\text { - El profesor de Cultura de la } \\
\text { Legalidad solicita texto. } \\
\text { - Diálogo/interacción con la } \\
\text { tutora. }\end{array}$ & - Narrar su experiencia. \\
\hline $\begin{array}{l}\text { 2. Conoordancia entre } \\
\text { singular y plural }\end{array}$ & $\begin{array}{l}\text { - La tarea de la asesora: pedirle la } \\
\text { redacción de su contexto } \\
\text { comunitario. } \\
\text { - La redacción previa de su enßayo } \\
\text { (borrador). } \\
\text { - Análisis de los errores (por él } \\
\text { mismo) a través de la lectura en } \\
\text { voz alta (relectura pausada). }\end{array}$ & $\begin{array}{l}\text { - La asesora, con la intención } \\
\text { de encontrar las temáticas } \\
\text { que habia previamente } \\
\text { narrado. } \\
\text { - Hl profesor de COF, como } \\
\text { solicitante de construcción } \\
\text { de su trabajo final. } \\
\text { - La inducción de la asesora. }\end{array}$ & $\begin{array}{l}\text { - la vinculación de su } \\
\text { experiencia con la redacción. }\end{array}$ \\
\hline $\begin{array}{l}\text { 3. Identificación de } \\
\text { clementos que organizan el } \\
\text { texto. }\end{array}$ & $\begin{array}{l}\text { - Análisis de su propio texto. } \\
\text { - Pasar al pizarrón para la } \\
\text { autocorrección. }\end{array}$ & $\begin{array}{l}\text { - La profesora utiliza el } \\
\text { diálogo sobre qué opina del } \\
\text { texto. }\end{array}$ & $\begin{array}{l}\text { - Sc vincula con su propia lengua } \\
\text { para reafirmarse. }\end{array}$ \\
\hline
\end{tabular}

Para distinguir la función de los artefactos utilizados en cada uno de los cambios, se encabeza la columna con la pregunta ¿Qué (se) hizo para mejorar? A partir de aquí, se nombran las formas en que se utilizaron para ejercer la tarea de la competencia en la literacidad.

Como se muestra en esta misma columna, los artefactos utilizados se agrupan en tres perspectivas de uso: 1) las tareas que dejaban los profesores de la materia y que servían como principio de motivación para ejercer la actividad propia del texto leído o escrito; 2) las actividades que se llevaron a cabo en el acompañamiento; y 3) el dominio de objetos que se usaron para apoyar la ejecución de las tareas o actividades. Los artefactos no solo dan cuenta de su uso, sino que ellos mismos contienen información de la cultura donde fueron creados, por tanto, tienen un carácter relacional según quién lo usa y qué actividad se realiza a través de ellos (Wartofsky, 1979).

Los usos de cada uno de los artefactos culturales se vincularon con el proceso particular del estudiante según sus características culturales en la tarea de desarrollar habilidades lingüísticas 
y cognitivas a partir de: 1) darse cuenta de la distinción de su lengua con el español; 2) conocer las diferencias lingüísticas, no tanto en las carencias o huecos de aprendizaje de la estructura sintáctica sino de un mundo conceptual distinto, las formas de definir lo otro y de nombrarlo (ejemplo: una palabra para ellos es una oración, a una palabra en español le hace falta el verbo, el nexo y el complemento, etc.); 3) hablar de su propia lengua, la distinción maya, sus derivaciones, y del español (nombra categorías distintas), enunciarse desde la dificultad de entender; 4) hablar mucho de lo suyo antes de escribir; 5) combinar elementos, incluso saltos de tema y aun así llegar a la idea; 6) hablar de su sentir y su pensar; 7) observar textos para identificar elementos.

Los artefactos, al contener información, adquieren una representación cultural en las prácticas sociales, por tanto, tienen un carácter mediacional con el ser humano en la medida en que se relaciona con su entorno (Holland, Cole, 1995). La acción mediadora del facilitador y de otros agentes en su contexto de aprendizaje adquieren la función intencional de acompañar de tres maneras: 1) la asignación de la tarea (un ensayo) por parte de su profesor; 2) las preguntas que realizaba la facilitadora para clarificar el tema; y 3) el ambiente de apertura en las sesiones de acompañamiento permitió expresar las ideas que quería trasmitir en el texto ensayístico. Estas acciones interactuaron unas con otras y con la experiencia de vida del estudiante, en relación con el contexto cultural de su procedencia. Al compartirla, se escuchaba a sí mismo y aportaba elementos que se acomodaron en la estructura de un ensayo.

Todo lo anterior tiene un vínculo con la parte emotiva del alumno, específicamente cuando se daba cuenta de la distancia que había entre sus formas de hablar-como estudiante que todavía no domina el español- y las formas de comunicación académica, en su mayoría totalmente nuevas. Muchas de las tareas lo confrontaban, y en estas circunstancias el único rescate era generar situaciones para narrar lo suyo (identidad, trayectoria, procedencia, problemáticas y logros, etc.). Estas experiencias eran insumos para conectar con las estructuras textuales académicas, conocer nuevos términos y otras formas de organizar sus ideas, sin desacreditar lo suyo.

En la tabla 5, se muestran los elementos que manifiestan el cambio desde el desarrollo de la dimensión cognitiva, específicamente en la planeación de la escritura académica. En la etapa previa de la escritura está implícita la lectura de varios documentos para identificar y argumentar las ideas. Se muestra el uso y aplicación de artefactos, las mediaciones y los significados. 
Tabla 5. Cambios, artefactos, mediaciones y significados derivados de la Dimensión Cognitiva sobre el descubrimiento de la construcción básica de la planeación escrita

\begin{tabular}{|c|c|c|c|}
\hline \multicolumn{4}{|c|}{ 2.1 DIMENSION COGNITIVA: PLANEACION DE UN TEXTO } \\
\hline $\begin{array}{l}\text { CAMBIO: } \\
\text { Descubrimiento de la } \\
\text { construcción básica de la } \\
\text { planeación escrita }\end{array}$ & $\begin{array}{l}\text { Qué hizo para mejorar } \\
\text { (Artefactos) }\end{array}$ & $\begin{array}{l}\text { Quién se lo encargó } \\
\text { (Mediaciones) }\end{array}$ & $\begin{array}{l}\text { Qué le significo/ emociones } \\
\text { (Significados) }\end{array}$ \\
\hline 1. Identificar ideas y conceptos & $\begin{array}{l}\text { - El trabajo del profesor de COE. } \\
\text { - La visión del párrafo en el pizarrón } \\
\text { (proyectada y escrita). } \\
\text { - El saber de la cxperiencia de la } \\
\text { situación que quiere plasmar en papel. } \\
\text { - Construir un glosario de conceptos } \\
\text { que no están dentro de su registro } \\
\text { linguístico. }\end{array}$ & $\begin{array}{l}\text { - El trabajo del profesor de COE. } \\
\text { - Acompañamiento de la asesofa. }\end{array}$ & $\begin{array}{l}\text { - Platicar detalladamente de su } \\
\text { experiencia con los migrantes en } \\
\text { Chiapas. }\end{array}$ \\
\hline $\begin{array}{l}\text { 2. Identificar ideas dentro de } \\
\text { un texto }\end{array}$ & $\begin{array}{l}\text { - La propia redaceión (trabajo del } \\
\text { profesor de COE), resaltando } \\
\text { elementos. } \\
\text { - E.l Power Point (tarea). }\end{array}$ & $\begin{array}{l}\text { - Hl profesor de COF le deja de } \\
\text { tarca un Power Point. } \\
\text { - L.a presión de otros compañeros. }\end{array}$ & $\begin{array}{l}\text { - Vínculo entre texto, estudiante y su } \\
\text { propio contexto (querer hacerlo bien). }\end{array}$ \\
\hline
\end{tabular}

La dimensión cognitiva no es independiente a la lingüística, al contrario, todas las dimensiones se intersectan entre sí con la misma temática y en los procesos del desarrollo de la competencia. Sin embargo, como característica esencial de este proceso, tienen la intención de hacer consciente al lector y al escritor de sus procesos cognoscitivos y de ser capaz de regular sus operaciones mentales.

Con la intención de hacer consciente el acto cognitivo de darse cuenta de la existencia de la organización de ideas en un texto, en la tabla 6 se muestran los artefactos, mediaciones y significaciones que fueron evidentes en el momento que el estudiante indígena universitario identificó las lógicas del orden en que están escritas las ideas y su importancia para comprender un texto. 
Tabla 6. Cambios, artefactos, mediaciones y significados derivados de la Dimensión Cognitiva sobre el descubrimiento de la planeación

\begin{tabular}{|c|c|c|c|}
\hline \multicolumn{4}{|c|}{ 2.2 DIMENSION COGNITIVA: ORGANIZACION DE IDEAS } \\
\hline $\begin{array}{l}\text { CAMBIO: } \\
\text { Descubrimiento de } \\
\text { organización de ideas } \\
\text { en la planeación escrita }\end{array}$ & $\begin{array}{l}\text { Qué hizo para mejorar } \\
\text { (Artefactos) }\end{array}$ & $\begin{array}{l}\text { Quién se lo encargó } \\
\text { (Mediaciones) }\end{array}$ & $\begin{array}{l}\text { Qué le significó/ emociones } \\
\text { (Significados) }\end{array}$ \\
\hline $\begin{array}{l}\text { 1. Identificar ideas y } \\
\text { conceptos. }\end{array}$ & $\begin{array}{l}\text { - Resaltar el concepto clave en } \\
\text { la lectura y relacionarlo con lo } \\
\text { que se menciona en clase. } \\
\text { - Identificar en la misma } \\
\text { lectura elementos relacionados } \\
\text { con el concepto (ejemplos, } \\
\text { explicaciones). } \\
\text { - Búsqueda en el diccionario } \\
\text { (virtual). }\end{array}$ & $\begin{array}{l}\text { - La tarea del profesor de } \\
\text { Cultura de la Legalidad. } \\
\text { - El diálogo con la asesora } \\
\text { para llegar a la identificación } \\
\text { de elementos de la lectura. } \\
\text { - El ambiente de apertura } \\
\text { para identificar distintas } \\
\text { formas de pensar. }\end{array}$ & $\begin{array}{l}\text { - Mencionar lo interesante } \\
\text { que le parece descubrir } \\
\text { conceptos y procesos } \\
\text { nuevos. } \\
\text { - Menciona que no lo hacía } \\
\text { anteriormente en la } \\
\text { preparatoria, y que ahora ya } \\
\text { puede (autoeficacia). }\end{array}$ \\
\hline $\begin{array}{l}\text { 2. Identificar ideas dentro de } \\
\text { un texto. }\end{array}$ & $\begin{array}{l}\text { - Subrayar una idea en el texto. } \\
\text { Compararla con otras ideas } \\
\text { escritas en el pizarrón. } \\
\text { - Identificar los componentes } \\
\text { de las ideas de la lectura y el } \\
\text { pizarrón. } \\
\text { - La escritura de lluvia de } \\
\text { ideas de acuerdo con su tema } \\
\text { en cl cuaderno. }\end{array}$ & $\begin{array}{l}\text { - La induceión de la asesora } \\
\text { para la detección de ideas } \\
\text { del texto solicitado por el } \\
\text { profesor de Cultura de la } \\
\text { Legalidad. } \\
\text { - Lluvia de ideas de los } \\
\text { saberes del estudiante en } \\
\text { relación con el contexto del } \\
\text { tema. } \\
\text { - Preguntas que apoyan a } \\
\text { contrastar el orden de ideas } \\
\text { de textos con otras } \\
\text { realidades. }\end{array}$ & $\begin{array}{l}\text { - Se observó el víneulo con } \\
\text { otros textos y, en sesiones } \\
\text { posteriores, la relación del } \\
\text { sujeto con otras ideas. } \\
\text { - Vínculo con saberes } \\
\text { previos: lo que sabía antes y } \\
\text { lo que ahora sabe. }\end{array}$ \\
\hline
\end{tabular}

Como se muestra en la tabla anterior, los artefactos culturales se exponen en relación con el uso y función de la tarea para desarrollar habilidades cognitivas que competen a la tarea de la lectura y la escritura. Sin embargo, tomando en cuenta la primera clasificación de los tipos de artefactos de Holland y Cole (1995), se identifican objetos esenciales que figuran en la tarea de la cultura académica, tales como: el texto científico, el diccionario virtual (computadora), el pizarrón, el cuaderno. Estos objetos no se analizan solos sino interrelacionados con otras esferas personales o sociales (Martos, Martos, 2014) del estudiante indígena, que se ponen en juego en la dinámica del acompañamiento. En este sentido, la columna de los artefactos no solo muestra el objeto en uso, sino la función de ellos en la tarea de hacer consciente el proceso cognitivo en la comprensión lectora.

El artefacto cultural se presenta entonces con carácter meramente cognitivo, en la medida que a través de él se adquiere conocimiento (Wartofsky, 1979). En la tabla anterior se muestran distintas habilidades asociadas con la lengua y comprensión textual. Estas están relacionadas con descubrir las formas de ordenar las ideas en el pensar de su propia disciplina contrastando con las suyas. En este sentido, la tarea de la medicación de la facilitación, como de los 
artefactos usados, buscaba que adquiriera el dominio de la habilidad para identificar ideas, categorías, argumentos varios, para también reconocer a través de ellos las distintas formas de pensar académico, social, frente a las propias que lo caracterizan como estudiante indígena en espacios universitarios.

En la dimensión cognitiva, la mediación de la facilitadora se inclinaba a orientar al alumno a darse cuenta de que hay otras formas de ordenar ideas y de expresarlas, igualmente válidas para su estudio; es decir, entender que es preciso saber leer las variaciones en los textos desde sus propios propósitos, códigos socioculturales y lingüísticos en los que están inscritos (Zavala, en Cassany, 2009).

La tarea de la mediación fue esencial para identificar las formas de conocer de su cultura con las lógicas del conocimiento académico y disciplinar. En esta dinámica resaltan seis perspectivas orientadoras: 1) agrupar elementos característicos de otros contextos, en vez de discriminar o clasificar; 2) retomar lo histórico o simbólico de la memoria histórica como un artefacto potente para mediar entre el contexto del alumno y las formas académicas del conocimiento; 3) comparar y contrastar ideas, procesos, imágenes, símbolos, sentires, pensares, para generar ideas; 4) asociar ideas del texto con ideas propias; 5 ) la escucha activa por parte de la facilitadora, es decir, evitar la intervención de la guía o la instrucción de cómo hacerlo, sino orientar en el proceso, pero a través de la escucha activa de sus narrativas que provocan la lectura; y 6 ) hacer uso del recurso de la memoria para asociar ideas y vincularlas con las lecturas.

La dimensión sociocultural se presenta como un eje transversal en las dimensiones lingüística y cognitiva, cobra sentido especialmente en los procesos de aprendizaje para adquirir la conciencia de los procesos que implican las distintas literacidades que participan en el aprendizaje académico y la práctica social.

La función de los artefactos pone en evidencia cómo se reflejan los constitutivos de la literacidad que compete a la cultura tradicional y académica, así como de la disciplina del estudiante. En concreto, uno de los reguladores de motivación más frecuente estuvo anclado en los relatos o narrativas de su contexto sociocultural. La memoria histórica fue un regulador cognitivo recurrente para vincular la actividad de la lectura y la escritura, a fin de identificar ideas, organizarlas y construir textos académicos.

La dimensión sociocultural estaá vinculada estrechamente con el artefacto, de manera que la idea simbólica que contiene se construye a partir del pensamiento asociado al contexto cultural en el que se sitúa (Holland, Cole, 1995), por tanto, los relatos expresados durante las sesiones de acompañamiento, vinculados a la memoria colectiva e histórica, apoyaron para identificar distintas maneras de organizar el pensamiento, unas arraigadas más en las creencias y otras sustentadas en argumentos con validez científica.

En suma, la dimensión sociocultural fue un detonante poderoso en el estudiante indígena, para vincular otros contextos, abordar de forma distinta lo académico desde sus vivencias, abrir 
el espacio al sentir su proceso, al pensar su propósito académico a través de conocer distintas culturas escritas.

\section{Conclusiones}

Las conclusiones que se presentan a continuación tienen la intención de mostrar tres aspectos esenciales en el desarrollo de la literacidad académica en el estudiante indígena universitario: primeramente, la variación de artefactos culturales que inciden para favorecer los cambios; segundo, la función de los artefactos culturales; tercero, la función mediadora del facilitador.

Hay una gran diversidad de artefactos culturales que participan en la tarea del desarrollo de la literacidad en el estudiante indígena universitario. Cada uno de ellos se presentan como objetos contendedores de información que representan las prácticas de la cultura de su procedencia (Holland, Colle, 1995; Wartofsky, 1979). En este sentido, se identificaron dos tipos de artefactos, los que competen a la cultura letrada universitaria, tales como objetos físicos indispensables para la realización de las tareas académicas; y los objetos arraigados en el recuerdo de la memoria del estudiante indígena, expresados a través de sus narraciones orales en el acompañamiento académico. Ambos tienen una clara incidencia en las dimensiones de la literacidad.

Los artefactos tomaron dos funciones esenciales dentro de la tarea del acompañamiento: 1) intervinieron como mediadores para el desarrollo del conocimiento de la literacidad académica y la distinción de otras literacidades, tales como la disciplinar y la de su propia cultura. La función mediadora apoyó para identificar distintas formas de ordenar las ideas, de exponerlas, argumentarlas para entender sus clasificaciones categóricas según el propósito textual; y 2) tomaron la función de intersectar o vincular las tres dimensiones en un solo proceso para el desarrollo de habilidades académicas. A partir de ellas, el estudiante se daba cuenta de los indicadores lingüísticos que competen a cada una de las literacidades, así como los procesos cognitivos y socioculturales que se requieren para la elaboración de los productos.

En la tarea de los artefactos de vincular las tres dimensiones, participa la función mediadora del facilitador orientando a la participación del alumno en sus tareas académicas. En el caso de la dimensión lingüística, las prácticas mediadoras más útiles fueron: 1) el desarrollo de ejercicios basados en problemas reales para su trabajo escolar, 2) la repetición de asignaciones hasta que el alumno quedara satisfecho con el mensaje que quería expresar, 3) redactar un guion de presentación y llevarla a cabo de forma oral, 4) la realización de ejercicios para identificar palabras homófonas, repetitivas y desconocidas, o 5) identificar, con ayuda de la asesora, los errores en sus textos fue clave en la mejora.

En lo referente a la dimensión cognitiva, se pueden señalar: 1) la realización de reflexiones acerca de lo que significan distintas lecturas, distintos tipos de lectura y relacionarlas con lo visto en clase, 2) la búsqueda en diccionario de palabras y conceptos, y a su vez relacionarlos con su experiencia de vida, 3) Identificar la idea y el mensaje en diferentes textos y elucidar la razón 
de que esté ahí y se exprese de esa manera, y 4) exponerlo en el pizarrón de la asesoría como medio de verificación de que se ha comprendido el significado de los textos, demostraron ser artefactos culturales idóneos para el desarrollo de las habilidades de literacidad.

Por último, en lo referente a la dimensión sociocultural, fue un eje transversal presente en todas las dimensiones, sobre todo en el sentido de darse cuenta de que los modos de expresión textual son simplemente formas de construir la realidad (Zavala, en Cassany, 2009). Asimismo, las vivencias del alumno, su vínculo con la comunidad, su memoria histórica y colectiva, también son elementos que inevitablemente permean en sus habilidades, sus cogniciones y sus voliciones. La posibilidad de elegir el tema sobre el cual versará un escrito, exponer de qué forma algo le es significativo, relacionar lo que dice un libro con lo que se vive en su comunidad y ponerle nombre "académico" a una experiencia situada de su comunidad, son elementos que permiten asignar significado y sentido al material que estudia. Se trata de un reforzador poderoso de su voluntad de seguir adelante, y al mismo tiempo se convierte en un potenciador de las habilidades en las dimensiones lingüísticas y cognitivas.

El artefacto cultural de Holland y Cole (1995) se prueba como elemento que potencia las habilidades de literacidad académica, tanto desde su acepción como algo físico (los libros, el diccionario, la computadora, etc.) hasta las prácticas (asignar tareas, revisar, expresar, etc.), e incluso los ideales o simbólicos, qué significa para la persona poner a dialogar los saberes de una cultura con los mecanismos académicos de otra.

De manera afín a los Nuevos Estudios de la Literacidad (NEL), que resaltan cómo lo subjetivo (propio del sujeto) está estructurado de forma histórica, contextual y culturalmente en los discursos comunicativos de los textos, el estudiante indígena descubre que sus discursos comunicativos y los pertenecientes a su comunidad, también tienen un lugar preponderante en su contexto.

Por último, usando lo dicho por Canagarajah (2003, en Zavala 2011: 56), se puede afirmar que "La nueva noción de escritura no implica un objeto, sino una actividad. Escribir ya no es sólo un producto (lingüístico) o un proceso (cognitivo), sino una práctica situada, social, material, ideológica e histórica". Así, el estudiante se da cuenta que, al enfocarse en desarrollar unas habilidades específicas, usando experiencias y cogniciones propias, pero aplicando las estructuras escolásticas de la comunicación académica, puede encontrar una vía para revelar lo suyo usando los medios de una cultura en la que se está involucrando.

\section{Referencias}

Aimes, P. (2002). Para ser iguales, para ser distintos: educación, escritura y poder en Perú. Lima: Instituto de Estudios Peruanos.

ANUIES (2006). Experiencias de atención a estudiantes indígenas en instituciones de educación superior. México: ANUIES. 
ANUIES-Fundación Ford (2005). Programa de Apoyo a Estudiantes Indígenas en Instituciones de Educación Superior. Memoria de Experiencias (2001-2005). México: ANUIES.

Barton, D.; M. Hamilton (2000). Literacy Practices. En Barton, D.; M. Hamilton; R. Ivanic (eds.). Situated Literacies. Reading and Writing in Context. Londres: Routledge, 7-15.

Canagarajah, A. S. (2003). Practicing Multiliteracies. En Matsuda, P. K.; A. S. Canagarajah; L. Harklau; K. Hyland; M. Warschauer. Changing Currents in Second Language Writing Research: A colloquium. Journal of Second Language Writing, (12), 151-179.

Canul, E. M.; Y. Fernández; M. E. Cruz; W. G. Ucan (2008). El papel de la universidad ante las demandas de los pueblos indígenas. Trace, (53). http://journals.openedition.org/trace/379

Cassany, D. (2009). Para ser letrados. Barcelona: Paidós.

Castoriadis, C. (1999). L'institution imaginaire de la société. París: Éditions du Seuil.

Ceja, B. (2013). Educación e identidad de los jóvenes de origen indígena, miembros de la Asamblea del proyecto Universidad Solidaria del Instituto Tecnológico y de Estudios Superiores de Occidente en el periodo 2006-2013. Tesis. México: ITESO.

Chouliaraki, L.; N. Fairclough (1999), en Zavala (2011). Discourse in Late Modernity. Rethinking Critical Discourse Analysis. Edinburgh: Edinburgh University Press.

Cole, M. (2003) Psicología cultural. Una disciplina del pasado y del futuro. Madrid: Ediciones Morata.

Didou, S.; E. Remedi (2006). Una oportunidad de educación superior para jóvenes indígenas en México. México: ANUIES.

Didou, S.; E. Remedi (2009). Los olvidados: acción afirmativa de base étnica en las instituciones de educación superior en América Latina. México: Juan Pablos Editor/Cinvestav.

Didou, S.; E. Remedi (2010). Programas de atención a estudiantes indígenas en educación superior en América Central: los sellos institucionales. México: Juan Pablos Editor/Cinvestav.

Flick, U. (2004). Introducción a la investigación cualitativa. Madrid: Morata.

Flores, P. (2006). El programa de apoyo a estudiantes indígenas en instituciones de educación superior ¿nivelador académico o impulsor de la interculturalidad? México: ANUIES.

Gayol, Y. (2014). La importancia de la literacidad. México: Campus Milenio.

http://campusmilenio.mx/index.php?option=com k2\&view=item\&id=9084:latimportanciadelaliteracidad\&ltemi $\mathrm{d}=1408$ tmpl=component\&print $=1$

Gerring, J. (2004). What Is a Case Study and What Is it Good for? American Political Science Review, (98), 341-354.

Hernández, G. (2016). Literacidad académica. México: Universidad Autónoma Metropolitana.

Herrera, G. (2006). Encuentro entre la cultura oral y la cultura escrita, una reflexión epistemológica en estudiantes indígenas en la Universidad Pedagógica Nacional. México: ANUIES.

Holland, D.; M. Cole (1995). Between Discourse and Schema: Reformulating a Cultural Historical Approach to Culture and Mind. Anthropology and Education Quarterly, 26(4), 475-490. 
Lea, M. R.; B. Stierer (2000). Student Writing in Higher Education: New Contexts. Higher Education, 40, 373-374. https://doi.org/10.1023/A:1004103221355

Lillis, T. (1997) New Voices in Academia? The Regulative Nature of Academic Writing Conventions. Language and Education 11(3): 182-199.

Lillis, T. (2001) Student Writing: Access, Regulation, Desire. London: Routledge.

Lillis, T. (2003). Student Writing as Academic Literacies": Drawing on Bakthin to Move from Critique to Design. Language and Education, 17(3), 192-207.

Locke, L.; W. Spirduso; S. Silverman (1987). Propuestas que funcionan: Una guía para la planificación de disertaciones y grandes propuestas. Newbury Park: Sage.

Marshall, C.; G. Rossman (1989). Diseñando la investigación cualitativa. Newbury Park: Sage.

Martos E.; A. Martos (2014). Artefactos culturales y alfabetización en la era digital. España: Universidad de Salamanca, 119-135.

Mendoza, J. (2014). La configuración de la memoria colectiva: los artefactos. Por caso, la escritura y las imágenes. Entreciencias, Diálogos en la sociedad del conocimiento, 2(3), 103-109.

Miles, M.; A. Huberman (1984). Análisis de datos cualitativos: un manual de métodos nuevos. Beverly Hills: Sage.

Moreno, E. (2014). La lectura académica y la teoría sociológica de Pierre Bourdieu. Enunciación, 19(2), 292-304.

Navarrete, Z.; A. Alcántara (2015). Universidades interculturales e indígenas en México: desafíos académicos e institucionales. Revista Lusófona de Educação, (31), 145-160. https://www.redalyc.org/pdf/349/34944227009.pdf

Olivera, I.; G. Dietz (2017). Educación superior y pueblos indígenas: marcos nacionales para contextualizar. Anthropologica, 35(39), 5-23. https://dx.doi.org/10.18800/anthropologica.201702.001

Ragin, Ch.; H. S. Becker (1992). What Is a Case? Cambridge: Cambridge University Press.

Romo, A. (2005). Evaluación del programa de tutoría de estudiantes indígenas. Programa de Apoyo a Universidades con Estudiantes Indígenas. México: ANUIES.

Salazar, C. (2015). La escritura académica universitaria: diferentes perspectivas de estudio. Revista Diálogos sobre Educación, 6(11).

Schmelkes, S. (2003). Educación superior intercultural: el caso de México. Encuentro Internacional Intercambio de Experiencias Educativas: Vincular los Caminos a la Educación Superior. México: Fundación Ford/ Unidad de Apoyo a las Comunidades Indígenas-Universidad de Guadalajara/ANUIES.

Schmelkes, S. (2008). Las universidades interculturales en México. ¿Una contribución a la equidad en educación superior? http://www.mineducacion.gov.co/cvn/1665/articles-175893 archivo pdf2.pdf

Schmelkes, S. (2009). Intercultural Universities in Mexico: Progress and Difficulties. Intercultural Education, 20(1), 5-17. 
Schmelkes, S. (2010). Programas de formación académica para estudiantes indígenas en México. Ponencia, Educación Superior de Carácter Étnico en México: Pendientes para su Reflexión. México: DIE-Cinvestav/Fundación Ford/Senado de la República.

Street, B. (1995). Social Literacies: Critical Approaches to Literacy in Development, Education and Ethnography. Londres: Longman.

Turner, J. (2003). Academic Literacy in Post-Colonial Times: Hegemonic Norms and Transcultural Possibilities. Language and Intercultural Communication, 3(3), 187-197.

Van Dijk, T. A. (2008). El discurso como estructura y proceso. Estudios sobre el discurso. Una introducción multidisciplinaria. Barcelona: Gedisa.

Vargas, F. (2013). Revisión entre iguales, escritura académica e identidad en la formación docente en una universidad colombiana. Tesis doctoral. Barcelona: Universidad Pompeu Fabra.

Vigotsky, L. (1994) The Problem of the Environment. En Van der Veer, R.; J. Valsiner (eds.). The Vygotsky reader. Cambridge: Blackwell Publishers.

Wartofsky, M. (1979). Models. Representation and the Scientific Understanding. Dordrecht/Boston/Londres: D. Reidel Publishing Company.

Yin, R. (2003). Case Study Research (3rd ed.). Thousand Oaks: Sage.

Zavala, V.; M. Niño-Murcia; P. Ames (2004). Escritura y sociedad. Nuevas perspectivas teóricas y etnográficas. Perú: Red para las Ciencias Sociales en el Perú.

Zavala, V. (2009). La literacidad o lo que la gente hace con la lectura y la escritura. En Cassany, D. (ed.). Para ser letrados. Barcelona: Paidós.

Zavala, V. (2011). La lectura académica y la agencia de los sujetos. Lima: Pontificia Universidad Católica de Perú.

Zavala, V. (2013). Dilemas y posibilidades de la literalidad en lenguas indígenas. XII Congreso Latinoamericano para el Desarrollo de la Lectura y Escritura, IV Foro Iberoamericano de Literalidad y Aprendizaje. Puebla, México: Consejo Puebla de Lectura. 